$9-1998$

\title{
Computer-Assisted Gait Analysis in Equine Orthopaedic Practice: The Case for Inverse Dynamic Analysis
}

Antonie J. van den Bogert

Cleveland State University, a.vandenbogert@csuohio.edu

Follow this and additional works at: https://engagedscholarship.csuohio.edu/enme_facpub

Part of the Biomechanical Engineering Commons

How does access to this work benefit you? Let us know!

\section{Original Citation}

van den BOGERT, A. J., 1998, "Computer-Assisted Gait Analysis in Equine Orthopaedic Practice: The Case for Inverse Dynamic Analysis," Equine Veterinary Journal, 30(5) pp. 362-363.

This Editorial is brought to you for free and open access by the Mechanical Engineering Department at EngagedScholarship@CSU. It has been accepted for inclusion in Mechanical Engineering Faculty Publications by an authorized administrator of EngagedScholarship@CSU. For more information, please contact library.es@csuohio.edu. 


\section{Editorials}

\section{Computer-assisted gait analysis in equine orthopaedic practice: the case for inverse dynamic analysis}

In this issue (p 384), Clayton et al. (1998) contribute a significant 'step forward' in the search for validated methodology and its interpretation as a means of advancing the subject of equine gait analysis as a clinical tool.

For hundreds, perhaps thousands of years, gait analysis has been the main clinical tool for diagnosis of lameness in the horse. Only relatively recently has gait analysis been supplemented by other techniques, such as X-rays and diagnostic nerve blocks. It is therefore not surprising that clinicians have developed remarkable skill and experience in evaluating and interpreting equine gait using no other tools than their own eyes. Since the early high-speed photography recordings in the late 19th century (Muybridge 1957), technological developments have made it possible to quantify the kinematics of equine gait more easily, more accurately, and objectively (Clayton 1996). Until now, however, this has not been shown to result in a better ability to quantify and characterise lameness, when compared to visual examination by an experienced clinician (Back et al. 1993). This is unfortunate, since gait is such an important part of equine health and performance. Also, it has been well established that equine gait is very reproducible and is fixed at an early age (van Weeren et al. 1993), indicating that gait analysis may identify small gait abnormalities as clinically relevant.

The situation in human orthopaedic practice is entirely different. Computer-assisted gait analysis has been used successfully as a research and clinical tool. This is partly due to the fact that, unlike in equine practice, there was no competition from centuries of experience in subjective clinical gait evaluation. In addition, however, human clinical gait analysis methods have been effective because of a better choice of mechanical variables to describe the results, and a similar success is possible in equine gait analysis.

Kinematic variables, such as marker trajectories, joint angles and angular velocities have been used frequently in the past 2 decades to quantify equine gait (e.g. van Weeren et al. 1993). These variables contain essentially the same information that is presented to the eye of the clinician, the only difference being the quantitative nature of the information and the increased spatiotemporal resolution. Resolution is important, because equine gait is sufficiently reproducible that even small changes in movement, or movements occurring on a very short time scale, both invisible to the human eye, are statistically significant. Nevertheless, it may be that those gait abnormalities that are visible to the human eye are also those that are clinically relevant, leaving the clinician's eye as an adequate tool.

A significant expansion of the clinical information is achieved by using kinetic variables. Kinetic variables are variables related to forces. Forces are not visible to the human eye, with the exception of certain effects on movement, such as acceleration of masses (by Newton's third law) or deformation of passive elastic material (such as a spring). But, when forces act on rigid material, or on complex systems of linked body segments, the human brain is not able to derive kinetic variables from visual gait information. This is where technical measurements provide a vast improvement. The force platform, measuring forces between hoof and ground, was introduced in the 1970s (Pratt and O'Connor 1976), and clinical applications were explored more recently (Merkens and Schamhardt 1988). These studies have shown that force plate signals are useful to quantify lameness, but do not provide good diagnostic information other than indicating the affected limb. Localisation of the disorder within the limb remains elusive.

A further quantum leap in information content of gait analysis can be gained by using inverse dynamic analysis. Inverse dynamic analysis treats the locomotor system as a system of linked rigid segments, with hypothetical torque motors at each joint representing the action of muscles. The analysis combines kinematic and force platform data to derive the time-histories of these joint torques (or moments) throughout the gait cycle. The methods have been well established in the literature, both in 2 (Winter 1979) and in 3 dimensions (Vaughan et al. 1991; van den Bogert 1994). Software to perform inverse dynamic analysis on any user-specified locomotor system, allowing for horses as well as man, is available from the major manufacturers of gait analysis equipment ${ }^{1.2}$.

Joint torques are related directly to the combination of muscle forces acting across the joint. Even more so than man, the horse with its 4 multijointed limbs, frequently acting as closedchain mechanisms, may redistribute its joint torques without visual gait changes. For instance, a visually identical hindlimb extension in late stance may be accomplished by only hip extensor torque, only knee extensor torque, or any combination of these. Inverse dynamic analysis allows us to 'see' these differences in muscle co-ordination. Three dimensional analysis also reveals torque components outside the sagittal plane, which reflect load distribution in collateral ligaments and cartilage rather than muscle co-ordination. One further useful step in inverse dynamic analysis is the quantification of joint power profiles. The mechanical power output (in Watts) of a torque motor is obtained by multiplying torque (in Newton metres) by joint angular velocity (in radians per second). This allows investigation of the sources of mechanical power for locomotion.

It must be stressed that results of inverse dynamic analysis may be sensitive to the protocol for data collection and the 
methods for data analysis. Since the horse is not a set of perfect rigid body segments, and kinematic data are contaminated by measurement errors and soft tissue deformation, results can only be an approximation. This is acceptable, as long as clinicians use the same methodology so that results can be compared between studies.

An indication of the potential applications of inverse dynamic analysis can be obtained from examples in the human literature. A well-known finding is that knee extensor torques during gait are significantly reduced after ACL injury. Inverse dynamic analysis provides a tool to monitor the patient's progress during rehabilitation and decide when surgical treatment is required (Andriacchi and Birac 1993). Using out-of-sagittal plane joint torques, it has been shown that a certain bracing method reduces the medial compartment loads in the joint (Lindenfeld et al. 1997). Especially noteworthy is the success of gait analysis, including inverse dynamic and joint power analysis, in surgical decisionmaking for children with cerebral palsy (Rose et al. 1993). Before such applications are possible, it is imperative that valid test protocols are established and normative data are collected (Ounpuu et al. 1991). The report by Clayton et al. (1998) is the first attempt to do precisely this for the equine forelimb during the trot. For the future development of equine clinical gait analysis, it is important that their protocols and results be studied critically, further refined, and developed finally into powerful clinical tools.

\section{A. J, van den BOGERT}

Department of Biomechanical Engineering (Wb3)

Lemer Research Institute

Cleveland Clinic Foundation

9500 Euclid Avenue

Cleveland, Ohio 44195, USA.
${ }^{2}$ Vicon bodybuilder, Oxford Metrics Ltd., Oxford, UK.

\section{References}

Andriacchi, T.P. and Birac, D. (1993) Functional testing in the anterior cruciate ligament-deficient knee. Clin. Orthop. 288, 40-47.

Back, W., Barneveld, A., Weeren, P.R. van, and Bogert, A.J. van den (1993) Kinematic gait analysis in equine carpal lameness. Acta Anat. 146, 86-89.

Bogert, A.J. van den (1994) Analysis and simulation of mechanical loads on the human musculoskeletal system, a methodological overview. Exerc. Sport Sci. Rev. 22, 23-51.

Clayton, H.M. (1996) Instrumentation and techniques in locomotion and lameness. Vet. Clin. N. Am: equine Pract. 12, 337-350.

Clayton, H.M., Lanovaz, J.L., Schamhardt, H.C., Willemen, M.A. and Colborne, G.R. (1998) Net joint moments and powers in the equine forelimb during the stance phase of the trot. Equine vet. J. 30, 384-389.

Lindenfeld, T.N., Hewett, T.E. and Andriacchi, T.P. (1997) Joint loading with valgus bracing in patients with varus gonarthrosis. Clin. Orthop. 344, 290-297.

Merkens, H.W. and Schamhardt, H.C. (1988) Evaluation of equine locomotion during different degrees of experimentally induced lameness. II: Distribution of ground reaction force patterns of the concurrently loaded limbs. Equine vet. J., Suppl. 6, 107-112.

Muybridge, E. (1957) Animals in Motion. Dover, New York (with reprints from the 1887 original).

Ounpus, S., Gage, J.R. and Davis, R.B. (1991) Three-dimensional lower extremity joint kinetics in normal pediatric gait. J. Pediatr. Orthop. 11, 341-349.

Pratt, G.W. and O'Connor, J.T. (1976) Force plate studies of equine biomechanics. Am. J. vet. Res. 37, 1251-1255.

Rose, S.A., DeLuca, P.A., Davis, R.B., Ounpuu, S. and Gage, J.R. (1993) Kinematic and kinetic evaluation of the ankle after lengthening of the gastrocnemius fascia in children with cerebral palsy. J. Pediatr. Orthop. 13, 727-732.

Vaughan, C.L., Davis, B.L. and O'Connor, J.C. (1992) Dynamics of Human Gait. Ist edn. Human Kinetics Publishers, Champaign, Illinois.

Weeren, P.R. van, Bogert, A.J. van den, Back, W., Bruin, G. and Bameveld, A. (1993) Kinematics of the standardbred trotter measured at $6,7,8$ and $9 \mathrm{~m} / \mathrm{s}$ on a treadmill, before and after 5 months of pre-race training. Acta Anat. 146, 154161.

Winter. D.A. (1990) Biomechanics and Motor Control of Human Movement, 2nd edn. Wiley, New York. 